\title{
Employability Skills Competence of Business Education Graduates in Managing Businesses
}

\author{
Edet Effiong Okon \\ Business Education Programme, Department of Vocational Education, Faculty of Education, University of Calabar, Calabar, Nigeria \\ Email address: \\ okon_e@ymail.com \\ To cite this article: \\ Edet Effiong Okon. Employability Skills Competence of Business Education Graduates in Managing Businesses. American Journal of \\ Management Science and Engineering. Vol. 5, No. 6, 2020, pp.70-78. doi: 10.11648/j.ajmse.20200506.11
}

Received: March 14, 2020; Accepted: April 10, 2020; Published: December 11, 2020

\begin{abstract}
This study determined the skill competence for managing businesses among fresh graduates of business education and achieved three objectives, answered three research questions and tested three null hypotheses. Descriptive survey design was used and the study was conducted in Calabar - Nigeria with a population of 61 fresh graduates and a sample of 60 respondents. Questionnaire generated data analysed using the dependent t-test statistical analysis. Findings are that there is no significant influence of record-keeping, accounting and marketing on the management of small-scale businesses among business education graduates in Calabar. Based on the findings of this study, the following conclusions are drawn: Recordkeeping and accounting skills are very highly needed; marketing skill is lowly needed in the management of small-scale businesses among Business Education graduates in Calabar. It is further concluded that record-keeping skill; marketing skill; and accounting skills have no significant influence on the management of small-scale businesses among Business Education graduates in Calabar. The recommendations made from the conclusion are that: Record-keeping skills are practically demonstrated by business education undergraduates to help them in the management of small-scale businesses on graduation; marketing skills be practically demonstrated by business education undergraduates to help them in the management of smallscale businesses on graduation; accounting skills are practically demonstrated by business education undergraduates to help them in the management of small-scale businesses on graduation.
\end{abstract}

Keywords: Business Education, Employability, Skill Competence, Business Operation, Graduates, Record-keeping, Marketing, Accounting

\section{Introduction}

Employability skills competence is one attribute that can give business education fresh graduates a boost as they are transiting from the enclosed training environment that characterize educational institutions to a dynamic and constantly changing business world. Business education graduates are those who have completed business education programme in tertiary institution. Business education itself has come of age and is now touted as an emerging programme needed in today's contemporary society where ownership of business has become the other of the day. Okon noted that Business Education belongs to the vocation-type and functional education designed to promote skills development for global competitiveness [13]. Its emphasis on acquisition of skills for self-reliance has been voiced by many scholars $[6,11$, 12].

The competitive environment under which the labour market and indeed the global economy operate can only favour graduates with skill competencies in diverse areas order than their subject matter/technical skills. The reality of today's business and work environment is already done on graduates of educational institutions. Employability skill competence manifest in practice as opposed to concept of Self-Efficacy and Self-Efficiency [16]. This theory states that every individual is required to perform tasks-routine especially 'new' ones - and it requires the ability to apply skills necessary to perform such tasks. The performance of these tasks is based on the competence drive of an individual described as "self-theories" or "efficacy beliefs" that the individual can always tackle assigned tasks [16]. This is further premised on intelligence that cannot be changed and construe ability as an inherent quality which undermines selfdevelopment of abilities. In view of the foregoing Ezenwafor and Olaniyi observed that the skills needed by teeming 
graduates are more than mere preparation for white collar job but for self-reliance [5].

A business owner may be an entrepreneur, a trader and can take any other form of business. Irrespective of the form it may take, certain skills are needed for the success of such business. Therefore, the entrepreneur or the business owner has to possess the skills required for the successful operation of such business. Among such skills, Oliveres laid emphasis on marketing skills, where the entrepreneur takes decision about the geographical location of the business, first contacting the customers [15].

Skills needed for managing small-scale businesses include record-keeping, accounting and marketing and negotiation skills. Accounting skills are skills needed in maintaining records showing the inflow and outflow of cash. Accounting skills are required by business education graduates for successful operation of small-scale business enterprise. Accounting here is the recording, summarising, and classifying, processing and communicating financial information resulting from business transactions for the purpose of making decisions by management. However, small-scale business owners scattered in the society may not have professional accounting skills to handle such records, thus putting a strong mandate on business educators to initiate and own small-scale businesses.

Recordkeeping is the process of recording transactions and events in an accounting system. The principles of accounting rely on accurate and thorough records; hence, record keeping is the foundation accounting. However, accounting and record keeping should not be used interchangeably. Accounting has a much broader definition than simply recording transactions in an accounting system. Accounting is used to identify events that need to be recorded, recording the transactions of these events, and communicating the effects of these transactions with people inside and outside of the company. Record keeping is only a small part of the broader definition of accounting.

According to Horsman, the recordkeeping system is the whole of people, resources, methods, procedures, data and knowledge with which an organisation moulds into concrete the required quality of its records [7]. The advent in technology has availed the recording system to be done both in manual and electronic form. Electronic records are records handled with the help of technology. To fulfil their function, records must not only be retrievable, accessible and readable but also authentic and reliable: they must be what they claim to be, and what they claim must be true.

Records are useful in accountability, business operations and historical purposes. The first two interests deal directly with why the record was created, as a product of a business process, the actions of a person, group of persons or any type of organization. Business activities generate 'records' which document the business activity and, after which, can function as evidence, evidence of what happened in the process. Since records serve as evidence, it must therefore be authentic and reliable. Every type of process will place specific demands on the authenticity and reliability of the records which it employs.
Providing evidence for accountability and business operations is not the only reason to consider documents as records and to preserve them. Records form an important part of organizational memory and all the records together make up society's memory. What applies to both the accountability function as well as the memory function, is that the relationships between the records and the process which generated them must be preserved, and thereby also the connection between related records.

Despite age-long demand for skills and the need for selfreliance in the society spanning through eras, the society is still battling to assume a stage where people are actually selfreliant. Business success, especially at the level of smallscale seems threatened as most small-scale businesses hardly last and profit is often stagnated. This may not be unconnected with lack of record-keeping, marketing and accounting skills. More worrisome is the low involvement of business education in issues related to management of business. Consequently, the arena for business operation continues to be dominated by people who lack the aforementioned skills. This constitutes grave problems which this study sought to address.

This study determined the skill competence for managing small-scale among fresh graduates of businesses. The study therefore sought to achieve the following objectives: To determine the competence level of:

1. Record-keeping skills competence for managing smallscale businesses among business education fresh graduates in University of Calabar.

2. Accounting skills competence for managing small-scale businesses among business education fresh graduates in University of Calabar.

3. Marketing skills competence for managing small-scale businesses among Business Education graduates in Calabar.

The study sought answers to the following research questions:

1. What is the level of skill competence in record-keeping for managing small-scale businesses among business education fresh graduates in University of Calabar?

2. What is the level of skill competence in account preparation for managing small-scale businesses among business education fresh graduates in University of Calabar?

3. What is the level of skill competence in marketing for managing small-scale businesses among business education graduates in Calabar?

This study tested the following null hypotheses. These are:

$\mathrm{HO}_{1}$ : Record-keeping skill does not significantly influence the management of small-scale businesses among business education graduates in Calabar.

$\mathrm{HO}_{2}$ : Accounting skill does not significantly influence the management of small-scale businesses among Business Education graduates in Calabar.

$\mathrm{HO}_{3}$ : Marketing skill does not significantly influence the management of small-scale businesses among Business Education graduates in Calabar. 


\section{Review of Related Literature}

\author{
Record-keeping skill competence and management of \\ businesses \\ Record keeping is an important aspect of a business
} operation. Irrespective of whether the business operator has professional skill in recording using double entry or not, a single and incomplete record could be maintained by business operators. Atah and Bessong opined that without record keeping it will be impossible to ascertain the level of profitability and the level of business susceptibility to fraud [3].

Record-keeping provides information which helps business owners/managers in making decisions and the absence of it can be likened to lack of or inadequate information, which can hinder the performance of businesses. Record-keeping has much influence on determination of profit of a business. It is an established fact that for profit to be determined properly, records must be kept rather than relying on human memory as human memory can be disappointed and not accurate. Records are also useful in monitoring cost and business performance generally. Records help in making such decisions as when and with what magnitude should the business be expanded. It is not advisable to just wake up one morning and decide to increase any aspect of the business's stock without consulting the business records as to whether it is feasible or not. Records are equally useful in attracting loans, aids and grants from financial institutions and the government. They also help to show that the operator is committed to the business. Though it is not advisable to advance credit to customers in small scale business, more often, one finds such requests difficult to decline. It is through a properly kept record that one can determine the credit worthiness of a customer, and it is also through that that one can know how much credit was advanced and on what date and time so as to minimise cases of argument. Moreover, managerial deficiency or efficiency can also be brought to the fore through the use of records. The keeping of records can lead to better performance not only in terms of profit but also in terms of trouble shooting and problem solving.

A study conducted by Ibrahim and Musah explored the relationships between record keeping and business performance among SMEs in Ghana [8]. Relying on a sample of 100 SMEs in the Tamale Metropolis, and employing simple regression analyses and Pearson Correlation Coefficient, we found a positive correlation between record keeping and business performance. In particular, we show that the two variables are linearly related. After swapping both the dependent and independent variables in the estimated models, we found a more robust impact on record keeping when it depends on business performance than when the latter depends on the former. We however could not show which variable causes changes in the other, necessitating further research efforts in this direction. While recognising the impact of record keeping on business performance, we conclude that at least in our study area, other performance metrics such as improved customer relations, access to sustainable finance, technology diffusion, and expanding the frontiers of access to internal and international markets are equally critical drivers of SME performance. This calls for conscious and coordinates efforts aimed at enhancing the performance of SMEs in Ghana.

Objectives of record keeping include the following: To provide an accurate, thorough picture of operating results; to permit a quick comparison of current data with prior years' operating results and budgetary goals; to offer financial statement for use by management, bankers and prospective creditors; to facilitate the prompt filing or reports and tax returns to regulatory and tax collecting government agencies; to reveal employees fraud, theft, waste and record keeping errors; to allow for fast, accurate, and reliable access to records, ensuring the timely destructions of redundant information and the identification and protection of vital and historically important records. It is necessary when a firm is seeking fund from a bank for expansion.

The benefits of record keeping cannot be over emphasized. Record keeping has become the foundation on which the totality of modern business depends. This is because without it, it will be impossible to ascertain the level of profitability and the level of business susceptibility to fraud. Record keeping and good record management is also essential for any corporate body to function effectively. If the records are kept over a period of time, they give background picture which can help organizational change. Continuing, they said it is not only accounting records that must be kept. In fact, personal records enable an accurate evaluation of personnel to aid administration of job selection. The specific benefits of record keeping include the following: It helps to avoid business failure; is useful for financial management planning and control; helps to make sound decisions; gives background picture which helps organizational change; is critical to business survival.

Accounting skill competence and management of businesses

Accounting process ranges from creation of business transactions, analyze and record the transactions in the journals by account name, post information from journals to ledgers, prepare a trial balance, journalize adjusting entries, post adjustments from the journal to the ledger, prepare an adjusted trial balance, journalize closing entries, post closing entries from the journal to the ledger, prepare a post closing trial balance, and prepare the financial statements. Accounting records are important as they are sources of information and thus, they must be numbered and stored properly for the purpose of record retrieval.

The importance of accounting in the management of businesses is acknowledged by Okolocha and Odimmega who observed that in every business establishment, the importance of accounting cannot be overemphasised [10]. Adekunle and Adejare in a survey study empirically investigate the effect of accounting records keeping on Small scale enterprises [1]. In line with the objectives of this study, a descriptive design such as personal interviews and questionnaire were employed as the major techniques for 
primary data collection. Data collected were analysed using both the qualitative and quantitative methods.

The descriptive statistics used were tables and percentages. Chi-square and analysis of variance (ANOVA) were employed to analyse data through STATA 10 version with the coefficient of determination (R2) 0.8974 which implied that $89.7 \%$ of the variation in financial performance could be explained by the level of accounting records keeping. Following the outcome of this study, it is therefore concluded that that there is a strong positive relationship between accounting records keeping and performance of small-scale enterprises.

In another study, Olatunji noted that small and mediumscale enterprises are gaining widespread acceptance as viable drivers of economic growth [14]. However, several of these enterprises demise without fulfilling expectations due to poor management arising from weak accounting structure. In view of this assertion, Olatunji conducted a study which examined the impact of sound accounting system on corporate performance of small and medium scale enterprises [14]. This was done by a survey carried out through questionnaire and analysed using the F-Statistic (ANOVA). Results showed that adoption of sound accounting system enhances performance of small and medium scale businesses. It was recommended that accounting professionals should customize accounting system and audits to the need and capacity of these categories of businesses, provide accountancy services or a fee, and adherence of small business operators to internal controls. The study conducted by Olatunji is directly related to the current study as both portrayed accounting skills as necessary for the management of businesses as evidence in the performance of the business [14]. Business education graduates who are equipped with accounting skills are therefore expected to do well in businesses, especially small-scale enterprises.

In Kamau who conducted a study on "the influence of accounting records on the financial performance of small and medium enterprises in central business district in Nairobi County, where the author remarked that small and medium scale enterprises are gaining wide spread acceptance as viable drivers of economic growth and need a sound accounting and internal control system [9]. The study sought to establish whether a relationship exists between accounting systems, the manner in which accounting records were maintained by SMEs and their financial performance. The study adopted a descriptive research design on SMEs in Nairobi Central Business District. The study sampled 391 SMEs in Nairobi Central Business District. Systematic sampling technique was used to sample SMEs. Descriptive statistics and regression analysis was used to analyse the findings. The study found that revenue and expenditure accounts play a major role in ledger accounts. For ledger accounts to be effective, revenue and expenditure accounts must be well prepared to limit chances of negative financial performance of SMEs in Nairobi County. It found that an improvement in keeping and preparing purchases and sales ledgers can result in improved financial performance. It also found that all the SMEs in Nairobi CBD keep purchases and sales ledger, cash book, revenue and expenditure accounts, statement of income and balance sheet. It found that most SMEs neutrally agree that purchases ledger shows all purchases returns of the business, sales ledger shows all returns to the business and sales ledger shows all the receivables of the business. Finally, the study found that a large number of SMEs prepare balance sheets as they convey substantial information about the financial strength and current performance of an enterprise.

This study has implications for the current study. First, the study, despite not focusing on category of business owners who are knowledgeable in principles of accounting laid emphasis on accounting skills. Secondly, the study clearly spelt out the need for business operators to improve their skills in accounting.

Accounting records keeping is essential for decision making which invariably affects performance of small-scale enterprises. It is recommended that the owners and managers of the small-scale enterprises should embrace proper accounting records keeping practices for effective financial performance in their business. Most accounting entries maintained by small-scale businesses appear as single entry. According to Eric and Gabriel, the single-entry system is an "informal" accounting or bookkeeping system where a user of this system makes only one entry to enter a business financial transaction [4]. It generally includes a daily summary of cash receipts and a monthly record of receipts and disbursements (worksheets). A cheque book, according to them, is a single-entry bookkeeping system where one entry is made for each deposit or cheque written. Receipts are entered as a deposit and a source of revenue. Cheques and withdrawals are entered as expenses. If a manual system is used, in order to determine the revenues and expenses, worksheets to summarize the income and expenses in different categories are to be prepared. Bookkeeping software and spread sheets are also available to do this.

The emphasis of this system is placed on determining the profit or loss of a business. It got its name because transactions are either recorded as revenue (deposit) or expense (withdrawal). Since each entry is recorded only once, debits and credits (recording method required for the double entry system) are not used to record a financial event. While the single-entry system may be acceptable for tax purposes, it does not provide a business with all the financial information needed to adequately report the financial affairs of a business.

Marketing skill competence and management of businesses

Marketing skills are important because they address something fundamental to the field: the role of marketing in business and society. Improvements in marketing skills have large and potentially transformative effects on small businesses.

Moreover, improvements in marketing skills offer a different pathway to profits than improvements in finance skills. Finally, the effects of improved marketing skills are 
not uniformly distributed among small businesses. Small businesses, the majority of which are micro businesses with less than five employees, are especially common - and their role is especially crucial - in emerging markets. Small businesses are distributors for larger firms; they ensure those others' goods reach otherwise hard to reach markets [17]. A study conducted by AndersonMcdonald sought to address a significant constraint to performance among businesses in emerging markets: marketing skills. Improvements in marketing skills offer the possibility of increased growth and prosperity; however, there exists substantial evidence that it is not abundant among small businesses [2]. We present evidence from the first randomized controlled trial to examine the impact of marketing skills, relative to finance skills, on firm performance. The empirical setting of the study is among small business owners in urban and slum neighbourhood across Cape Town, South Africa. We offer intensive marketing and sales training to one randomly selected group of firm owners, intensive finance and accounting training to another randomly selected group of firm owners, and no training to a control group. For the next eighteen months, we measure the effects of the interventions on the practices and performance of these small businesses. Our findings are threefold. One, marketing skills and finance skills each has a positive and significant effect on firm performance, including increases in: survival, employment, sales, and profits. Two, the pathway to profits differs for marketing relative to finance: profit effects are roughly equal across the two interventions, yet entrepreneurs who receive marketing training tend to achieve these gains by increasing sales and hiring more staff (i.e. growth focus) while those who receive the finance training tend to enhance profits by decreasing costs (i.e. efficiency focus). Three, the returns to business skills training differ depending on individual characteristics. Consistent with a 'growth focus' explanation, marketing/sales training appears to be most beneficial to small business owners who (ex-ante) have been less exposed to different business contexts. By contrast, and in line with an 'efficiency focus' explanation, entrepreneurs who have been running more established businesses (prior to training) tend to benefit more from finance/accounting skills.

The outburst of technology has gradually matured to a level where business operation is becoming more sophisticated and requires some level of competence in the use of these technologies. Fresh graduates of business education cannot afford to lag behind and cannot continue in the usual order of writing application and moving round in search of jobs that do not exist. Again, business owners, especially those who operate on a small-scale cannot operate without the application record-keeping, accounting marketing and negotiation skills. Anything in the contrary continue to widen the gap in unemployment; business failures and poverty that have grown so high and already a source of worries and constituting perennial problems which this study seeks to address.

\section{Research Methods}

This study adopted the descriptive survey design and the study was conducted in Calabar. Calabar is the capital city of the present Cross River State, a status, which the city has maintain from the era of Colonial Rule, South Eastern State and the defunct Cross River State before the creation of Akwa Ibom State. The city of Calabar has remained relevant in the history of Nigeria, especially in commerce and education, considering its early contact with European/colonial administration, which prompted commercial and business development and the introduction of commercial subjects in the curricula of schools. The population consisted of 61 fresh graduates of the 2017/2018, including two spills over from previous sessions whose names are in the convocation list. The sample size was 61 respondents as the entire population was purposively selected. However, only 60 respondents were reached and questionnaire administered on them. Skill Competence and Management of Small-scale Business Questionnaire (SNMSSBQ) generated data for the study. Data obtained was analysed using the dependent t-test statistical analysis.

\section{Results}

Research Question One

What is the level of skill competence in record-keeping for managing small-scale businesses among business education fresh graduates in University of Calabar?

Table 1. Descriptive statistics of the level of skill competence in record-keeping for managing small-scale businesses among business education fresh graduates in University of Calabar.

\begin{tabular}{lllll}
\hline S/N & ITEM & TOTAL SCORE & MEAN & REMARK \\
\hline 1 & Competence in sales record-keeping & 212 & 3.67 & 3.50 \\
2 & Competence in purchase record-keeping & 209 & 3.53 & VHCL \\
3 & Competence in cash record-keeping & 212 & 3.60 & VHCL \\
4 & Competence in stock record-keeping & 216 & 3.00 & VHCL \\
5 & Competence in debt record-keeping & 180 & 3.50 & HCL \\
TOTAL & & 1,037 & 3.4 & VHCL \\
GRAND MEAN & & 207.4 & \\
\hline
\end{tabular}

N=60; VHCL = Very High Competency Level; HCL = High Competency Level; LCL = Low Competency Level; VLCL Very Low Competency Level

The result presented as answers to research question one, shown in Table 1 shows that fresh graduates have a very high level of competence in record-keeping with a weighted mean of 3.50 .

Research Question Two

What is the level of skill competence in account 
preparation for managing small-scale businesses among business education fresh graduates in University of Calabar?

Table 2. Descriptive statistics of the level of skill competence in account preparation for managing small-scale businesses among business education fresh graduates in University of Calabar.

\begin{tabular}{llll}
\hline S/N & ITEM & TOTAL SCORE & MEAN \\
\hline 1 & Competence in sales forecasting & 172 & REMARK \\
2 & Competence in advertising & 219 & 3.90 \\
3 & Competence in pricing & 112 & 1.90 \\
4 & Competence in determining discount & 98 & 1.63 \\
5 & Competence in retention & 180 & 3.00 \\
TOTAL & & 781 & 12.08 \\
GRAND MEAN & & 156.2 & LCL \\
\hline
\end{tabular}

$\mathrm{N}=60$

VHCL = Very High Competency Level; HCL = High Competency Level; LCL = Low Competency Level; VLCL Very Low Competency Level

The result presented as answers to research question two, shown in Table 2 shows that fresh graduates have low competence in marketing with a weighted mean of 2.42 .

Research Question Three
What is the level of skill competence in marketing for managing small-scale businesses among business education graduates in Calabar?

Table 3. Descriptive statistics of the level of skill competence in marketing for managing small-scale businesses among business education graduates in Calabar.

\begin{tabular}{|c|c|c|c|c|}
\hline $\mathbf{S} / \mathbf{N}$ & ITEM & TOTAL SCORE & MEAN & REMARK \\
\hline 1 & Competence in preparing capital account & 215 & 3.58 & VHCL \\
\hline 2 & Competence in preparing cash account & 222 & 3.70 & VHCL \\
\hline 3 & Competence in preparing sales account & 199 & 3.32 & HCL \\
\hline 4 & Competence in preparing purchase account 1 & 201 & 3.35 & VHCL \\
\hline 5 & Competence in determining profit and loss & 226 & 3.77 & VHCL \\
\hline TOTAL & & 1,063 & 17.77 & \\
\hline GRAND MEAN & & 212.6 & & VHCL \\
\hline
\end{tabular}

VHCL = Very High Competency Level; HCL = High Competency Level; LCL = Low Competency Level; VLCL Very Low Competency Level

The result presented in Table 3, which provides answers to research question three shows that fresh graduates of business education have very high level of competence in the management of small-scale business.

Hypothesis one

$\mathrm{H}_{1}$ : Record-keeping skill does not significantly influence the management of small-scale businesses among Business Education graduates in Calabar

Table 4. Related t-test of no significant influence of record-keeping on the management of small-scale businesses among Business Education graduates in Calabar.

\begin{tabular}{llll}
\hline Variable & $\mathbf{N} \sum \boldsymbol{d}$ & $\sum_{\boldsymbol{d}} \mathbf{2}$ & t-cal \\
\hline Record-keeping & 207.40 & 15824.02 & 1.01 \\
Management & 193.20 & & \\
\hline
\end{tabular}

$\mathrm{N}=60 ; \mathrm{df}=58 ;$ Significant Level $=.05 ;$ Criticalt $=2.02$

The result presented in Table 4 shows that the calculated tvalue of 1.01 is less than the critical t-value of 2.02, degree of freedom being 58 at .05 Significant Levels. Based on this finding, the null hypothesis, "there is no significant influence of record-keeping on the management of small-scale businesses among business education graduates in Calabar" is sustained. This means that competence in record-keeping has no significant influence on the management of smallscale businesses among fresh graduates of business education.

Hypothesis two

$\mathrm{HO}_{2}$ : Marketing skill does not significantly predict competence in managing small-scale businesses among business education graduates in University of Calabar.

Table 5. Related t-test of no significant influence of marketing on the management of small-scale businesses among Business Education graduates in Calabar.

\begin{tabular}{|c|c|c|c|c|}
\hline Variable & $\mathbf{N} \sum d$ & $\sum 2$ & & t-cal \\
\hline Marketing Skills & 156.20 & 71.6 & 7240.16 & 0.84 \\
\hline Management of Small-scale & 193.20 & & & \\
\hline
\end{tabular}

$\mathrm{N}=60 ; \mathrm{df}=58 ;$ Significant Level $=.05 ;$ Criticalt $=2.02$

The result presented in Table 5 shows that the calculated tvalue of 0.84 is less than the critical t-value of 2.02 , degree of freedom being 58 and .05 significant levels. Based on this finding, the null hypothesis, "there is no significant influence of marketing on the management of small-scale businesses among business education graduates in Calabar" is sustained. This means that competence in marketing has no significant influence on the management of small-scale businesses among fresh graduates of business education in University of Calabar.

Hypothesis three

$\mathrm{HO}_{3}$ : Accounting skill does not significantly influence the 
management of small-scale businesses among Business Education graduates in Calabar.

Table 6. Related t-test of no significant influence of accounting skill on the management of small-scale businesses among Business Education graduates in Calabar.

\begin{tabular}{llll}
\hline Variable & $\mathbf{N} \sum \boldsymbol{d}$ & $\sum_{\boldsymbol{d}}^{2}$ & t-cal \\
\hline Accounting Skill & 212.60 & \\
Management of Small-scale & 193.40 & 97.002 \\
\hline
\end{tabular}

$\mathrm{N}=60 ; \mathrm{df}=58 ;$ Significant Level $=.05 ;$ Critical $\mathrm{t}=2.02$

The result presented in Table 6 shows that the calculated tvalue of 2.01 is less than the critical t-value of 2.02, degree of freedom being 58 and .05 significant level. Based on this finding, the null hypothesis, "accounting skill does not significantly influence the management of small-scale businesses among Business Education graduates in Calabar" is sustained. This means that competence in accounting skill does not significantly influence the management of smallscale businesses among fresh graduates of business education in University of Calabar.

\section{Discussion of Findings}

Record-keeping skills and management of small-scale businesses

The finding from answer to the research question related to this variable reveal that record-keeping skill is very highly needed. Again, finding based on test of hypothesis one shows that record-keeping has no significant influence on the management of small-scale businesses among Business Education graduates in Calabar. The finding from test of hypothesis one is an indication that most small-scale business managers (owners) do not possess record-keeping skills, hence, can hardly keep records of their business transactions. On the other hand, this lack of skills underscores the skill need revealed in the answer to the research question that record-keeping is very highly needed. The finding that recording-keeping skill is very highly needed by owners of small-scale businesses affirms the need for business education graduates to venture into ownership of small-scale businesses. This finding further buttress the findings of Ibrahim and Musah in a study, which explored the relationships between record keeping and business performance among SMEs in Ghana [8]. Relying on a sample of 100 SMEs in the Tamale Metropolis, and employing simple regression analyses and Pearson Correlation Coefficient, we found a positive correlation between record keeping and business performance. In particular, we show that the two variables are linearly related. After swapping both the dependent and independent variables in the estimated models, we found a more robust impact on record keeping when it depends on business performance than when the latter depends on the former. We however could not show which variable causes changes in the other, necessitating further research efforts in this direction. While recognising the impact of record keeping on business performance, we conclude that at least in our study area, other performance metrics such as improved customer relations, access to sustainable finance, technology diffusion, and expanding the frontiers of access to internal and international markets are equally critical drivers of SME performance.

Accounting skills and management of small-scale businesses

The findings from the research question and hypothesis related to this variable reveal that accounting skill is very highly needed but does not significantly influence the management of small-scale businesses among Business Education graduates in Calabar. The importance attached to accounting skill as revealed in the answer to the research question is further affirmed by the views of other scholars and means that the operators of small-scale businesses investigated did not actually acquire such skills, which is why the findings from test of the hypothesis indicated a nosignificant-influence. However, Adekunle and Adejere in a survey study empirically investigate the effect of accounting records keeping on Small scale enterprises [1]. In line with the objectives of this study, a descriptive design such as personal interviews and questionnaire were employed as the major techniques for primary data collection. Data collected were analysed using both the qualitative and quantitative methods. The descriptive statistics used were tables and percentages. Chi-square and analysis of variance (ANOVA) were employed to analyse data through STATA 10 version with the coefficient of determination (R2) 0.8974 which implied that $89.7 \%$ of the variation in financial performance could be explained by the level of accounting records keeping. Following the outcome of this study, it is therefore concluded that that there is a strong positive relationship between accounting records keeping and performance of small-scale enterprises. Accounting records keeping is essential for decision making which invariably affects performance of small-scale enterprises. It is recommended that the owners and managers of the small-scale enterprises should embrace proper accounting records keeping practices for effective financial performance in their business.

Accounting process ranges from creation of business transactions, analyze and record the transactions in the journals by account name, post information from journals to ledgers, prepare a trial balance, journalize adjusting entries, post adjustments from the journal to the ledger, prepare an adjusted trial balance, journalize closing entries, post closing entries from the journal to the ledger, prepare a post closing trial balance, and prepare the financial statements. Accounting records are important as they are sources of information and thus, they must be numbered and stored properly for the purpose of record retrieval

Marketing skills and management of small-scale businesses

The findings resulting from answer to research question and hypothesis related to this variable reveal that marketing skill is lowly needed and does not significantly influence 
the ability to manage small-scale businesses among Business Education graduates in Calabar. This finding would have been resulted from less attention paid in on the promotion and creation of market for the business. A typical scenario would have been to have the findings indication a high marketing skill need and significantly influencing the management. Again, it would have been that the operators may not have regarded marking skills as very important and this has been a serious and common factor affecting the management and subsequently, the growth and development of small-scale businesses. Marketing skills are important because they address something fundamental to the field: the role of marketing in business and society. Improvements in marketing skills have large and potentially transformative effects on small businesses. Moreover, improvements in marketing skills offer a different pathway to profits than improvements in finance skills. Finally, the effects of improved marketing skills are not uniformly distributed among small businesses. Small businesses, the majority of which are micro businesses with less than five employees, are especially common - and their role is especially crucial - in emerging markets. Small businesses are distributors for larger firms; they ensure those others' goods reach otherwise hard to reach markets [17].

\section{Conclusions}

Based on the findings of this study, the following conclusions are drawn: Record-keeping and accounting skills are very highly needed; marketing skill is lowly needed in the management of small-scale businesses among Business Education graduates in Calabar. It is further concluded that record-keeping skill; marketing skill; and accounting skills have no significant influence on the management of smallscale businesses among Business Education graduates in Calabar.

\section{Recommendations}

The recommendations made from the conclusion are that:

1. Record-keeping skills are practically demonstrated by business education undergraduates to help them in the management of small-scale businesses on graduation.

2. Marketing skills be practically demonstrated by business education undergraduates to help them in the management of small-scale businesses on graduation.

3. Accounting skills are practically demonstrated by business education undergraduates to help them in the management of small-scale businesses on graduation.

\section{References}

[1] Adekunle, O. and Adejare, A. T. (2014). The analysis of the impact of accounting. records keeping on the performance of the small-Scale enterprises. International Journal of Academic Research in Business and Social Sciences (IJARBSS), 4 (1): 47-58.
[2] Anderson-Macdonald, S. (2014). The impact of marketing (versus finance) skills in firm performance: Evidence from a randomised controlled trial in South Africa. London: World Bank.

[3] Atah, C. A and Bessong, E. B. (2018). Impact of record keeping for sustainability of small-scale business operators for national economic development in Nigeria. Nigerian Journal of Business Education, 5 (1), 102-114.

[4] Eric E. O. Gabriel D. (2012). Challenges of book keeping on small and medium scale enterprises (SMEs) in Kwaebibirem District: The Case of Appex Global (Ghana) Limited. International Journal of Business and Management Cases 1 (2), 1-12.

[5] Ezenwafor, J. I. and Olaniyi, O. N. (2017). Extent of technical and ICT skills needs for entrepreneurial success by business education students in Ondo and Ekiti states. Nigerian Journal of Business Education, 4 (2), 235-244.

[6] Federal Republic of Nigeria-FRN (2014). National policy on education. Abuja: NERDC Press.

[7] Horsman, J. (2001). Electronic record-keeping. Dutch: Den Haag Publishers.

[8] Ibrahim, M. and Musah, A. (2014). Record keeping and the bottom line: Exploring the relationship between record keeping and business performance among small and Medium Enterprises (SMEs) in the Tamale Metropolis of Ghana. Research Journal of Finance and Accounting 5 (2): 107-117.

[9] Kamau, R. M. (2015). The influence of accounting records on the financial performance of small and medium enterprises in central business district in Nairobi County. Unpublished MBA THESIS submitted to the UNIVERSITY OF NAIROBI. Available at: http://www.erepository.uonbi.ac.ke/bitstream/handle/11295/93 $377 /$ Kamau The $\% 20$ influence $\% 20$ of $\% 20$ accounting $\% 20$ recor ds $\% 20$ on $\% 20$ the $\% 20$ financial $\% 20$ performance $\% 20$ of $\% 20$ sma $11 \% 20$ and $\% 20$ medium $\% 20$ enterprises $\% 20$ in $\% 20$ central $\% 20$ bu siness $\% 20$ district.pdf? sequence $=1 \&$ isAllowed $=y$

[10] Okolocha, C. C. and Odimmega, C. G. (2019). Employability skills development of financial accounting students in secondary school in Anambra State. Nigerian Journal of Business Education, 6 (1), 80-93.

[11] Okon, E. E. (2020). Business education in the contemporary global society. England: Lambert Publishing.

[12] Okon, E. E. \& Chukwurah, C. C. (2017). International Marketing in the Domain of Business Education in Nigerian Universities and Industry Best Practices. Journal of International Business Education (JIBE), Neilson Journals Publishing, United Kingdom, 12: 2017, 49-70. http://www.neilsonjournals.com/JIBE/abstractjibe12okonchuk .html.

[13] Okon, E. E. (2011). Quality Assurance Indices and the Teaching of Business Education in Federal Universities in South-South Zone of Nigeria. Unpublished M.Sc. (Ed.) Dissertation, Postgraduate School, University of Uyo, Uyo - Nigeria.

[14] Olatunji, T. E. (2013). The impact of accounting system on the performance of small and medium-scale enterprises in Nigeria. International Journal of Business and Management Invention, 13-17. Available at: https://web.facebook.com/effiblink1991/posts/292182433457 9114?notif_id=1585256107108642\&notif_t=feedback_reactio n_generic_tagged. 
[15] Oliveres, S. O. (2015). Business graduate skills: Competencybased model. In: M. K. Ayub; D. Bank; E. E. Okon; A. Q. Ghassan; S. L. O. Olivares and S. T. Martinez (Eds.). Diverse contemporary issues facing business management education. USA: IGI Global, http://resources.igi-global.com/production/ proofs/9781466664494/5a9e9d76-8e98-4b8c-9212-

54e517defac7.pdf.
[16] Tilak, J. B. G. (2002). Vocational education and training in Asia. Hand bookon educational research in the Asian pacific Region.

[17] Viswanathan, M.; Rosa, J. A. \& Ruth, J. A. (2010). Exchanges in marketing systems: The case of subsistence consumermerchants in Channai, India. Journal of Marketing, 74 (3), 117. 